\title{
A Hermeneutical Analysis of Women's Experiences and Perception about Empowerment with Microcredit Programs in Lower Sindh, Pakistan
}

\author{
Sarah Wali Qazi ${ }^{1}$ \\ Muhammad Zaki Rashidi ${ }^{2}$ \\ Humair $\mathrm{Ali}^{3}$
}

\begin{abstract}
This research study explores the experiences of women about empowerment which are realized through the utilization of microcredit. During the Literature iteration, it was evident that there is a positive verdict between women empowerment and microcredit; also it mitigates the feminization of poverty. This study has gauged the women's life experiences that how they precipitate their thoughts for realizing empowerment with microcredit. This is a qualitative study with abductive research approach, philosophy is hermeneutic phenomenology with the feminist paradigm, and overall research design supports the truth of several subjective perspectives and would help in constructing the meaning of empowerment from the Sindh's context. This study is conducted in the context of Sindh; the respondents are women who availed microcredit from microfinance institutions and banks which are registered under State Bank of Pakistan and Security Exchange Commission of Pakistan. For collecting the data, in-depth interviews have been conducted by using the interview protocol and they have been continued till the saturation level. Under the interpretative phenomenology, nomothetic and idiographic analysis has been practiced for mining the data. From the women's perspectives, it is gauged that small credit empowers women and also strengthen their families. This research would be valuable for the policy maker of microfinance they design policies accordingly.
\end{abstract}

JEL Classification: M14, M21, G21

Keywords: Feminization of Poverty, Hermeneutic Phenomenology, Microcredit, Women Empowerment.

\section{INTRODUCTION}

According to Kapila, Singla, and Gupta (2016), growing body of facts proposes that empowerment of women is crucial for the development of the countries and they require financial as well as societal support for realizing this phenomenon and this fact was also supported by Banerjee and Sain (2016). Prominent attention has been given to women empowerment as a development policy, as poverty is deeply 'engendered' because of women's imbalanced access to resources and economic, social, and political power in most of developing country's contexts (Zoynul \& Fahmida, 2013). The empowerment is achievable by two ways; the revolution in power and other is the advancement of power. If the power does not change and become inflexible then no empowerment can be realized; for empowerment, the power should be transformed from single person to another person (Luttrell, Quiroz, Scrutton, \& Bird, 2009; Ali \& Hatta, 2012).

1- Shaheed Zulfiqar Ali Bhutto Institute of Science and Technology, Karachi. Email: sarawali.qazi@szabist.edu.pk 2- Iqra University, Karachi.

3- Mohammad Ali Jinnah University, Karachi.

Volume 16

Number 2

July-December $2018 \quad 01$ 
Empowerment is conceptualized into multi-dimensional concepts which are economic empowerment (making monetary and investment decisions, producing income, and be participative in economic sphere); social and political empowerment (high involvement in society's decisions, mobility in the neighbourhood, changing society's norms, self-confidence, self-motivation, collective action, political participation, voting, awareness regarding human rights); and familial empowerment or Improved well-being of household (better education and nutrition for the children, improved household expenditures, improved overall consumption pattern, access to better medication and health facilities) (Hennink, Kiiti, Pillilger, \& Jayakaran, 2012; Malhotra, Schuler, \& Boender, 2002). Therefore, social, cultural and financial elements are required for achieving and realizing empowerment but Akram and Hussain (2011) and Ali and Alam (2010) deliberated that financial aspect specifically microcredit as an effective tool in strengthening poor people and eminent for the empowerment of women (Dobra \& Stiftung, 2011). Agarwal (2016) endorsed the previous studies and contributed that microcredit is a structured group-based plan in which small loans are provided to poor people or weak segment of the society explicitly poor rural women without any collateral. These programs are designed for the poor who are in the susceptible position through this financial provision they would be able to fight against poverty and fetch self-confidence. The purpose of microcredit programs is to make poor people capable so they can produce income, survive happily, and improve the well-being of the family (Basher M. A., 2010).

In our Patriarchal society, where male dominancy conquers and women are under the men's power and subject to discrimination, control, exploitations, dishonor, violence, and subjugation. Women face more obstacles in creating their own identity because it is the myth of these societies that men have the right to work outside. Due to this, skilled women are compulsorily excluded from economic actions; and whatever work they do is neither recognized nor accounted (Weiss, Hussain, \& Sathar, 2001; Ullah \& Sohail, 2013).

In most of the developing countries, women's vulnerable position can be observed and if we see Pakistan's context then here women's role is still under the concern while we are living in the 21st century. Ali and Hamid (2010) expressed that in most of the developing countries women role are redefined and are fortified to be in national economic endeavors. However, women here face cultural and religious taboos in spite of the point that they comprise half of the population and their struggles are playing the vigorous part in the economy in both formal and informal sectors. Hartmann (2008) agreed that women participated in threshing, harvesting, sewing, teaching etc. they are also involved in poultry and livestock trades, and also work for small and medium industries.

Kim, et al. (2007) observed that most of the lower class women are employed in very low paid jobs, so side by side small businesses enhance their incomes which improve living standards of their families and hence Self Help Group (SHG) and microfinance would reduce poverty and strengthen the women. Decision-making power of women in various aspects has been advanced through microfinance and SHG. A study by Chowdhury (2008) also exhibited that those respondents who availed microfinance loans have the higher level of decision making power as compare to those who did not avail these loans, other than this, they also had the confidence to take part in economic development (Aruna \& Jyothirmayi, 2011).

MFIs provide funds to women to fulfill their families' financial needs and to boost

02 July-December $2018 \quad$ Volume $16 \quad$ Number $2 \quad$ JISR-MSSE


entrepreneurial spirit among women so they can take decisions and educate them, mentor them by executing strong network for women's (Strong, 2007). A Study was conducted over women empowerment in Nepal and Pakistan, which disclosed that women nurture self-assurance and can be good decision makers through MFIs activities. However, in both the countries, social and cultural perception prevents women to participate and that's why women would not contribute much and feel disempowered as they were (Gobbi, Dhakal, \& Hijazi, 2005).

Women faced certain major restrictions while in obtaining and utilizing microcredit which is considered as a strategy to alleviate poverty, includes less access to financial services, lack of power over microcredit etc. On the other hand, MFIs of the developing countries have the restrictions like, lack of sustainability of their own institution, shortcoming in definition, measurement, and analysis of poverty among women as in the developing countries like Pakistan the exact statistics are missing, other problem is shortcoming in measurement of women's empowerment as no quantitative or qualitative tool is specifically design for measuring the impact of microcredit on the women empowerment (Nasir, 2013).

As far as Sindh is concerned, the study is conducted by Rais, Mangan, Kumbhar, Hussain, and Sahito (2016) in district Dadu for assessing the microfinance impact on small farmers but not on women, in which they had concluded that farmers who invest microloans for farming business are getting higher revenues.

Women and men are sharing different proportions under poverty, according to UNDP, $70 \%$ of the women are under the poverty around the globe and as per the UNIFEM minimum $60 \%$, world's poor are women. They are considered poor because they are earning less than $\$ 2$ per day. Poor women are going through the severe poverty by reason of malnutrition, access to education and medical facilities, few employment opportunities, lack of money and extraordinary responsibilities and household burden which eventually resulting feminization of poverty (Bhat \& Lakshmi, 2002).

According to the IMF report 2017, Pakistan's 29.5\% population is living under the poverty, ministry of planning development and reforms said that approx. 55 million people are living below the poverty line as per the latest data of Household Integrated Economic Survey data (HIES) 2017. Sindh is considered the second largest poor province of Pakistan after Baluchistan according to the statistical bulletin 2017 of State Bank of Pakistan (SBP) although rural Sindh and rural Baluchistan are not comparable due to the variation in their population (Statistical Bulletin-November, 2017, 2018). Pakistan is ranked fourth worst country for women according to women, peace and security index, 150th ranking out of 153 reflect that women face the highest discrimination and lowest financial inclusion (Pakistan ranked fourth among worst countries for women, 2017).

\section{STUDY OBJECTIVE}

The main objective of this Hermeneutic phenomenological study is;

- To explore the voices of women of Sindh about their lives that how their lives are transformed after utilizing the effective tool of microfinance that is microcredit,

- To extract women perceptions and experience about their empowerment in the different spheres like economic, social, political and family well-being.

- This study is intended to gauge the lived experiences of women with the empowerment and identifying the contribution of microcredit in attaining it in the different spheres of their life like economic, social and political, familial.

\begin{tabular}{lllll}
\hline JISR-MSSE & Volume 16 & Number 2 & July-December 2018 & 03
\end{tabular}


Only a few research studies like Ali and Hatta (2012) study, with this perspective, are published in our context which is mostly empirical in nature, empowerment is the process of realization which comes under the categorical variable and it is difficult to measure it numerically that's why hermeneutic study is selected for gauging the feelings and perception of the people.

This study would indicate the structural meaning of empowerment from the Pakistani women's perspective, and on the other hand this study is helpful for microfinance practitioners and policy makers to critically examine the status of MFIs, imply new means and design policies for promoting women empowerment initiatives more effectively. This study is significant because it considers the beneficiaries experience and point of views which were not explored earlier in this context.

\section{LITERATURE REVIEW}

This chapter is designed to focus on the core concepts of the study that is microcredit, women empowerment, and their nexus. Also, after the iteration of the literature, it is possible to identify the research gap. This chapter is designed with the topical structure.

\section{Microfinance and Microcredit Concept}

Microfinance is the phenomenon of providing financial assistance to poor people as many, so as possible, so they can utilize their abilities for their own development. Microcredit, on the other hand, is one of the products of microfinance which is related to small loans, micro represent small and credit means loans, these loans lend to the poor who can exploit their capacities and become productive economic contributors (Dobra \& Stiftung, 2011). Microcredit is the element of microfinance as microfinance is not only bound with the provision of small loans but other financial services like insurance or savings are also the part of microfinance (Hunt \& Kasynathan, 2002; Kwasi \& Seini, 2014).

It must be stressed excessively that the vitalizing inspiration driving the microfinance development was the reduction of poverty. Microfinance had also offered the possibility to allay poverty while compensating for itself and earning a profit by doing great. This prospective maybe more than anything represents the rise of microfinance onto the worldwide stage (Agarwal, 2016).

Microfinance is for the poor people. Maybe the basic inquiry about the microfinance was that either it is an effective way to reduce poverty against other poverty mitigation policies or not. (Agarwal, 2016; Rai \& Ravi, 2011). Bui (2014) supported the argument that microfinance might not be a successful tool for mitigation of poverty in the US. Schreiner (1999) examined US microenterprise projects and found that albeit a few projects can move some individuals from welfare to independent work, people became entrepreneurs (Evelyn \& Osifo, 2018). Also, Schreiner (1999) demonstrated that the individuals who are effective in the move have education, own resources, abilities, and related experiences (Bui, 2014). Seibel (2010) examined the effect of microenterprise advancement projects and called into inquiry their viability as an antipoverty methodology (Addai, 2017). Different studies reach more uncertain decisions about the viability of microfinance as an approach instrument (Fenton, Tallontire, \& Paavola, 2017). Snow and Buss (2001) study microfinance programs in sub-Saharan Africa

04 July-December $2018 \quad$ Volume $16 \quad$ Number $2 \quad$ JISR-MSSE 
and provided the fact that the microfinance can be proven an effective policy for mitigating the poverty if it is evaluated properly (Handayani, 2013; Katheu, 2013; Snow \& Buss, 2001).

\section{Microfinance Industry in Pakistan}

After Aga Khan Rural Support Program initiated in 1980 in Pakistan, National Rural Support Program and Sarhad Rural Support Program were established in the microfinance sector. These Rural Support Programs were introduced to provide financial services to the poor. In the year 1996 Rural Support Program (RSP) started to specialize in a certain sector and led the foundation of Kashf Microfinance bank. Pakistan Microfinance Network (PMN) originated in 1995 and began to play a role as an emergent Microfinance Provider (MFP). In 2000, Pakistan Poverty Alleviation Fund (PPAF) provided its first loan to MFI, and State Bank of Pakistan (SBP) initiated a microfinance unit. Khushhali Bank was established in 2001 with the collaboration of Government of Pakistan. 2001 was the beginning of a new era in microfinance according to Microfinance Ordinance. SBP, with the ordinance and subsequent regulations, laid the foundations to stimulate the establishment of an inclusive financial system.

In Pakistan's microfinance industry, three peer groups players are present that are: non-government microfinance institutions (NGO-MFIs), microfinance banks (MFBs), and rural support programs (RSPs). SBP provided the supervisory and regulatory framework to MFBs who are licensed under the Microfinance Institutions Ordinance 2001. The MFBs have been acknowledged in relation to Pakistan's regulatory framework, and due to that in 2010 it was recognized by the Economic Intelligence Unit (EIU) and amongst fifty-four countries it became fifth-ranked in terms of overall environment and setting for operating microfinance business (Pakistan Microfinance Network: Annual Report, 2012). For Non-Bank Microfinance Institutes (NBMFI) like NGO-MFIs, Security and Exchange Commission of Pakistan (SECP) has provided the regulatory framework and National Financial Inclusion Strategy (NFIS) (National Financial Inclusion Strategy Pakistan, 2014). These policies were crucial to introduce despite the fact that in $20154.2 \%$ growth was recorded but still in Pakistan situation of financial inclusion illustrates a dismal image. Only Sixteen percent (16\%) are categorized as banked from the adult population and formal financial services are used by only twenty-three percent (23\%) of the population. In rural areas, the situation is worst where only fourteen percent (14\%) are banked. In these cases, the thing which needs the concentration is the women banked percentage which is only eleven percent (11\%) in an adult population. Pakistan's continues to lag behind in financial inclusions, the picture of this state can be evident more when it is regionally compared (Basharat, Arshad, Abbass, \& Aziz, 2015).

The central bank of Pakistan has been performing the significant role in the growth of the microfinance industry since 2000. In Pakistan, the microfinance sector is recognized globally for its strapping regulatory, strategic, and legal framework. In 2007, SBP formulated the national microfinance strategy with the approval of the Government of Pakistan for the sustainable growth of the sector (Strategic Framework for Sustainable Microfinance in Pakistan, 2011). SBP revised this strategy again in 2011 for the promotion of financial services which are needed by the low-income and poor segments of the society (Ayub-ul-Hasan \& Khan, 2012). 
Pakistan has a different regulatory system to administer the microfinance practices of the Microfinance Banks (MFBs). The MFBs are authorized and managed by State Bank of Pakistan although PMN also keeps an eagle eye on the operations of not only MFBs but MFIs and RSPs too. Considering the different needs and elements of microfinance, SBP has set up a different administrative and supervisory system for MFBs. Since its creation, the regulatory system or approach structure has seen different changes towards the improvement, on the premise of key stakeholders' opinion and appraisal of the developing needs and circumstances of the industry. To advance the mainstreaming of microfinance into the general financial framework, SBP supports the establishment of new MFBs and conversion of existing operationally workable MFIs into MFBs. The vicinity of a huge potential business and accessibility of an empowering strategy environment provide the opportunities for social as well as for commercial investors to explore this division of the financial market. As the results, $50 \%$ growth has been seen in overall gross microcredit portfolio, the number of borrowers, as well as loan cycle, has been increased (Munir \& Qasim, 2016; Muhammad, 2010; Asher \& Haider, 2017).

\section{Microcredit and Women}

Microcredit has been used in different countries for strengthening the women; also microfinance is considered as the key weapon against the poverty. Poverty has the direct link with women, it was discussed that women are poorer than men that's why microfinance institutions are targeting women for improving their families well-being and for the growth of the economy (Sinha, Mahapatra, Dutta, \& Sengupta, 2018). In the emerging economies, the susceptible position of the women is under the great consideration, the efforts are being made to encourage women so they can take initiatives, establish their businesses for the growth of economy, as the author also emphasizes that in developing countries women deal with the economic exploitation, sexual mistreatment, political injustice, and economic disparity. But through microfinance and other facilities provided by the microfinance institutions (MFIs), it is possible to generate entrepreneurs which surged their economy towards the sustainable high position (Anyanwu, 2004; Awojobi, 2013).

Hulme and Arun (2011) provided the evidence behind targeting women for microfinance. According to them, women are recognized as the poorest and vulnerable segments within the low salaried societies, although they contribute in income generating activities and save their expenditures. It is surmised from the literature that if women are also provided with the credit facility then they would be empowered in the same manner as the men (Hulme \& Arun, 2011; Agarwal, 2016). Women invest in productive physical and human capital, take the risk, adopts technologies, smooth consumptions and timely interest payment reflect their economic empowerment (Bruno, 2013; Varghese, 2011). Women considered as the 'broker' of the educational position of the families, nutritional, and health conscious of their children, so their encouragement would eventually impact the whole society. So, it was concluded that participation of women in the microcredit initiatives has been considered influential in both manners i.e. their own socioeconomic welfare and their families (Kumar, Hossain, \& Gope, 2013; Li \& Rama, 2015). The critics had opposed the ideas and shared that women borrowers' shoulders became overburdened due to the less level of control in their businesses, loan repayment responsibility, and enhanced duty of nourishment (Taylor, 2012). In this scenario, the developmental aim behind targeting women became eroded if the direct relationship between the repayment responsibility and utilization of personal loan had been ruptured

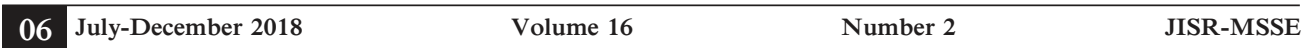


(Aggarwal, Goodell, \& Selleck, 2015). Then the question arises that why then women have been targeted for the microcredit? Analysts and researcher provided another fact behind this strategy, Peprah (2012) stated that it's not about 'access for women', though it's about 'women are accessible'. Women assumed to be trustworthy more than men in term of credit risk, they can easily be found in their homes and on the other hand they perceived more repayment pressure than men. The alternative rationale proposed that microfinance practitioners do not address the gender relations or its issues although target women for various reasons (Peprah, 2012; Mishi \& Kapingura, 2012).

If we view the stated history, we see that the microfinance is directly concerned with the empowerment of the poor. There are hordes of examples on the correlation between microfinance and women empowerment. This study is based on women empowerment paradigm, which is designed on the basis of gender policies and that concept was proposed by different NGOs. The researchers of the microfinance pasture, from the many years, explored the gender impact of microfinance programs (Zoynul \& Fahmida, 2013). The central aim of this paradigm is to provide the poor women with credit facilities (Alsop \& Heinsohn, 2005; Mayoux, 2005).

According to the author, in access to microfinance services gender discrimination also occurs. Even in successful microfinance programs contribution to women empowerment often restricted to the certain level. Women empowerment cannot occur just because of microcredit rather it also needs strategically designed programs (Ali \& Hamid, 2010). Each and every organization has different ways or programs for women empowerment. The author has drafted a report on Taraqee Foundation's (TFs) Micro-Finance and Economic Development program (MFED) whose main motto is to alleviate poverty through microcredit and saving facilities to both women and men to support gender equality (Mayoux, 2005).

This foundation used Road Journeys model that showed that women take initiative in setting their enterprises though they have faced certain challenges including family opposition and demands. They used this model to know how many women are really benefitted from loans, what risks and opportunities they faced with. Even they monitor the implication of strategies and how efficiently they worked (Panigrahi \& Satapathy, 2014).

\section{Mayoux's Three Construct Model of Empowerment}

Women empowerment is the evolution of liberty of preference and accomplishment to shape one's life (Nasir, 2013). These three constructs are economic, social and political like the levels of income creation and mobilization, and the third aspect is improved living standard which is usually recognized as familial empowerment.

According to Mayoux (2005) and Golla, Malhotra, Nanda, and Mehra (2011), empowerment has multiple dimensions. These are:

Women Economic Empowerment: The author suggests that women can be capable to contribute in the economy and make better decisions for their economic position. The Economic Empowerment as the word suggests is related to the financial aspect like income generation, women's participation in economic activities etc. (Sohail, 2014). The list of economic women empowerment indicator is given below;

\begin{tabular}{llll|l}
\hline JISR-MSSE & Volume 16 & Number 2 & July-December 2018 & 07
\end{tabular}




\section{Table 1}

Indicators to Measure Economic Women Empowerment

\begin{tabular}{ll}
\hline Constructs & \multicolumn{1}{c}{ Indicators } \\
\hline Women's Participation in the economy & - Establishing business (increased women \\
& entrepreneurs) \\
& - Ownership of Credit for economic activities \\
Women's Success & - Effectively and efficiently implemented the \\
Control over assets & - Ownership of Productive assets \\
& - Contribution to household income \\
Productivity & - Access to Market
\end{tabular}

Source: (Golla, Malhotra, Nanda, \& Mehra, 2011)

Women Social and Political Empowerment: Women can involve in decision making, be autonomous, self-confident and can manage their household income. There are the indicators which show social, political, and legal empowerment. Social is related with the participant's own life decisions about family, household, and self-decisions not only the decision making but participant's mobility in the community, autonomous position; respect and value in the family and neighborhood, confidence level are also the part of social empowerment. Legal awareness and knowledge about the country politics, rights and votes would be considered as the political empowerment.

\section{Table 2}

Indicators for Women Social and Political Empowerment

\begin{tabular}{ll}
\hline Constructs & \multicolumn{1}{c}{ Indicators } \\
\hline Decision Making & - Women involvement in households decision \\
Mobility & - Freedom to movement \\
Status within the community and at & - Respect in the family \\
home/ Respect & - Ability to take challenges and believe in own self \\
Self-confidence & - Legal laws and regulations awareness \\
Political Empowerment & - Knowledge about rights \\
\hline
\end{tabular}

Source: (Mayoux, 2005; Nair, 2013)

Familial Empowerment: Improved living standards are also known as familial empowerment in which overall consumption pattern of the participant's family has been considered, children's nutrition, health, and education are also the part of this empowerment. How much well-being has been improved in the context of a participant, her male and children, not only this but how much man contributes after her earnings are also significant indicators in this category, 
Table 3

Elements for Measuring Improved Living Standards

\begin{tabular}{ll}
\hline Constructs & \multicolumn{1}{c}{ Indicators } \\
\hline Men contribution to income & - Female-headed households \\
Increased Children Well-being & - Improved Nutrition \\
& - Access to better health facilities \\
Poverty reduction & - Access to better education \\
& - Improved Overall household wellbeing \\
\hline
\end{tabular}

Source: (Golla, Malhotra, Nanda, \& Mehra, 2011; Mayoux, 2005)

This diagram is built on the basis of above indicators having multi-dimensions of empowerment that are economic empowerment, social and legal empowerment, and increased well-being shows the overall process of empowerment by keeping these directions in view, the interview has been gathered and assessed. This figure reflects that how savings and microcredit lead to income generation activities and employment, also saving and credit indirectly fetch social and legal empowerment. Betterment in household expenditure and consumption lead towards the improved well-being of family that is familial empowerment.

Figure 01 Mayoux Three Constructs of Empowerment.

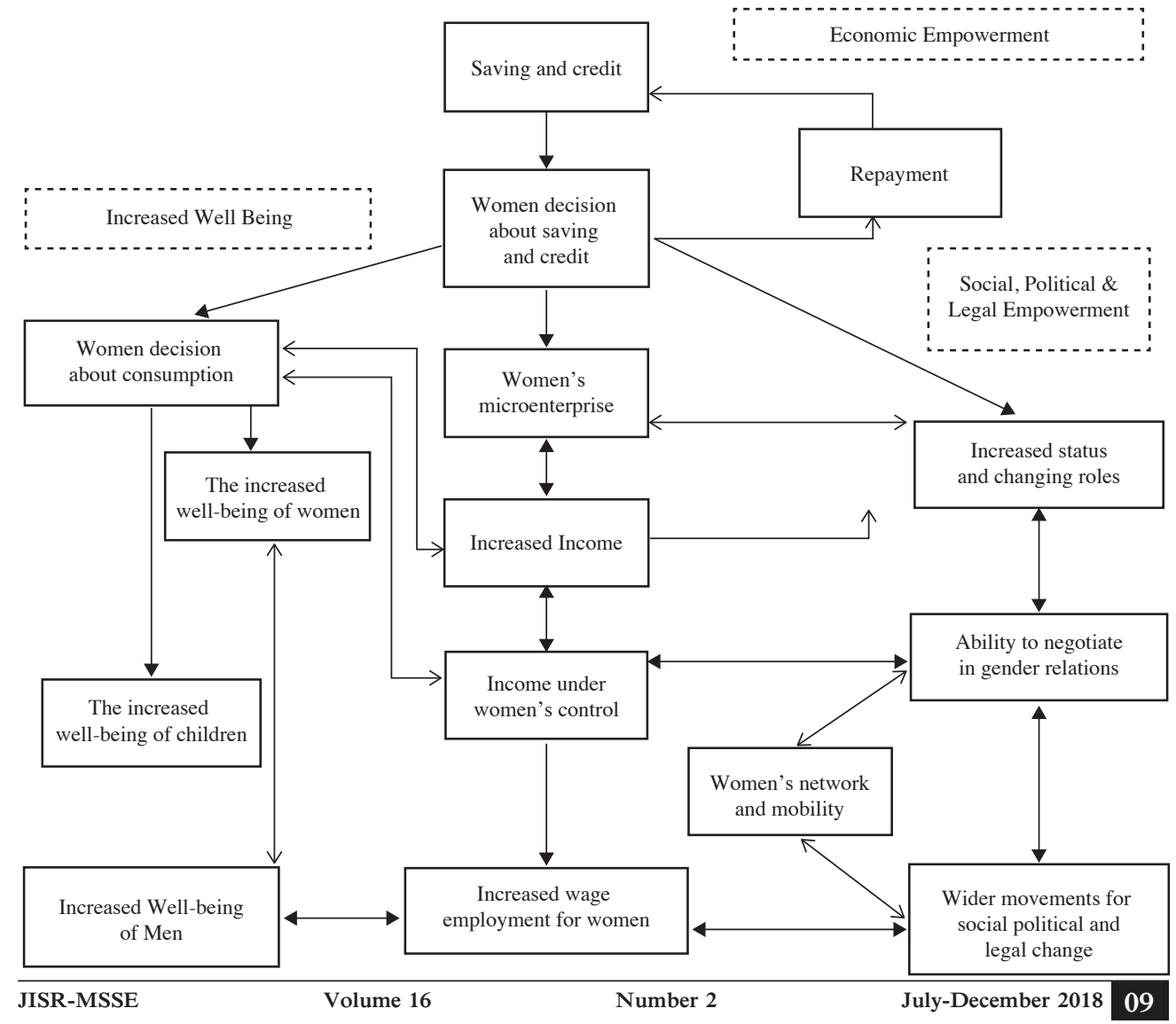




\section{Research Gap}

The purpose of this research is to explore women experiences about empowerment through microcredit that would be gained from women's verbal explanations and expressions, also from their feelings and perceptions, and how this small loan transforms their lives. The measurement of women empowerment is the problematic aspect because it is not possible to quantify this theoretical concept and abstract it. The different indices are available which provide the quick view of this phenomenon but they are limited because they use few measurable variables, ignore subjective experiences, leave details and other ontological issues that enrich the whole picture. The Gender Gap Index (GGI), Gender Development Index (GDI), and Gender Empowerment Measure (GEM) were introduced as the measures of empowerment but were limited to the women economic contribution and gender inequality with few variables of political participation.

Chaudhry, Nosheen, and Lodhi (2012) conducted the study in Southern Punjab, Pakistan, for measuring empowerment through these dimensions but they concluded that the study without answering the question of how empowerment can be measured. They contended that there are few determinants which are not considered in the dimensions but in the context of Pakistan, they are essential to be considered like religious views and regional aspects which interact in this patriarchal society. They concluded with the idea that empowerment concept varies from culture to culture and region to region; either multivariate analysis would resolve the problem or any qualitative method can reveal the truth behind the empowerment (Saigol, 2011; Chaudhry, Nosheen, \& Lodhi, 2012).

This study had been designed with the focus on how to capture the life experience of women who availed microcredit and recognize their own empowerment which varies from culture to culture. The study was constructed on the phenomenology which can fill the clear gap between theory and practice in the context of finding the association between women perceptions and experiences of gaining empowerment and microcredit program.

\section{RESEARCH METHODOLOGY}

This study is based on hermeneutical phenomenological philosophy. The background of an individual is not explicit, Sammel (2003) emphasizes that Heideggar believes that the world and the people's point of views are indissolubly associated in social, cultural and historical context. This sort of phenomenological study is also the experience lived by the researcher because they adjust themselves with the ontological nature of the fact. Ontology deals with reality. The truth can lie outside the person or may be generated by the individual consciousness (Cohen \& Crabtree, 2006). In the hermeneutical phenomenological study the reality is seen as an individual own mapping to distinctive circumstances. From now on, it is rested on the conviction that realities are numerous (Kafle, 2013).

"How we know and what we know" is the basis of epistemology. The idea of this knowledge is the contribution of research towards generating knowledge again. According to Hartley (2007), epistemology is the procedure through which the analyst makes the information claim. The hermeneutic phenomenological study is based on the ground of the "Subjective Knowledge" (Kafle, 2013). This study focuses on the life experiences of women. I am using hermeneutics phenomenological method in this research because every woman perceives, understands and interprets her own experiences regarding initiating the business,

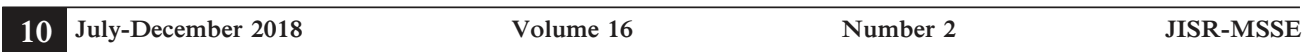


empowerment, and the well-being of the family on her own. The ontological perspective of this research is that reality or truth is constructed by women themselves and the epistemological standpoint is the overall knowledge generation regarding women status and microcredit role in their empowerment, this knowledge has been gained through the whole hermeneutics phenomenological research process.

The process of research which is based on abductive research strategy starts with the description of the everyday activities and meanings of participants and then themes, categories and concept emerged which create the base of an understanding of the phenomenon or the problem (Reichertz, 2007).

This research strategy incorporates the interpretations and meanings, intentions and motives, that people practice or use in their routine lives which direct their behavior and relieve them from the central point in social research and theory.

\section{Participants and Sampling Method}

In this study non-probability, purposive multivariate sampling is used for the selection of participants. Purposive or judgmental sampling is employed because the respondents who are selected can answer the interview questions and would allow the researcher to fulfill study objectives (Sekaran \& Bougie, 2010). Not only this, but the multivariate type enabled the researcher to take the sample which is based on the variation where a different participant can be the part of it. Participants are women, who live in Sindh and have availed microcredit at-least a year ago as for taking in-depth interviews they must be having some experience to share.

\section{Context and Settings}

This research is conducted in rural and urban areas of Sindh, where MFI are operating. According to the Sharma and Varma (2008), the context of women's empowerment delivers the thought of describing, overcoming, and challenging barriers in a woman's life. Due to the centuries of ignorance, passive inertia, and conservatism, women's role in this specific society has been disregarded; their social progress and change are still not achieved because they are deprived of making their fair contribution (Sharma \& Varma, 2008).

This study was conducted in the natural settings and context is significant in the qualitative study as it uncovers the social meaning and true essence from a broad spectrum to the specifics of how contextual settings influence individuals. Sindh province of Pakistan was selected for the study which is the second largest province in terms of the active borrowers. There are valid reasons behind choosing Sindh as the context of this study, the researcher is basically from Sindh and understands the languages spoken in Sindh. In rural areas of Sindh, most people speak Sindhi or Urdu. The researcher was also aware of the diverse culture of Indus civilization although the sub-cultures were also explored during the interviews. The researcher had some idea about it and prior visits to the region made her able to understand the values and traditions of those people. This study was on the women and for the women so the researcher must seem to belong to their culture so the clear insights and in-depth information can easily be extracted. Microcredit is considered for the empowerment of women in the context of this study but it is also considered that empowerment cannot be gauged solely its economic, social, political and technological contexts are significant.

\begin{tabular}{llll|l}
\hline JISR-MSSE & Volume 16 & Number 2 & July-December 2018 & 11
\end{tabular}


Cultural context is the bit advanced in the metropolitan cities of Sindh as their exposure is different and this acquaintance is now traveling towards the lower Sindh areas as well. Political environment to economic and social environment with diverse opportunities have different power on the thoughts of the women, therefore, this study is based on the hermeneutics phenomenology as experiences vary sub-culture to sub-culture and women interpret what they experience (Connell, 2003).

\section{Data Collection Procedure}

The data collection has been done by using the in-depth interviews in which interview protocol and observation protocol has also been used. The observation and interview protocol has been designed by considering the Cole (2014) and Graflund (2013) studies. The motive of developing observation protocol is to record reflective notes. The pilot testing has been completed by a pilot interview from the Sujawal district and then interview protocol has been amended accordingly. For the validity check, a protocol has been directed to the experts for their opinions and for ethical permission has also been taken from the microfinance institutions whose clienteles have been interviewed. The data has been congregated in three different visits of four to five days and during the interviews with women, reflexivity was practiced (Finlay, 2009). The interviews have been gathered till the level of saturation, it is the point where no new data has emerged. 34 interviews have been conducted, out of which 33 are considered for the analysis and the one interview has been seen fake, so it has eliminated.

\section{Ethical Consideration}

Researcher triangulation has been struggled to make sure the credibility of the study, transcripts have been sent to the researchers of the same field who have to meet the same conclusion, this sort of researcher triangulation has been practiced.

\section{Interpretative Phenomenological Analysis and Discussion}

The interviews have been taken from 34 women, one interview has been dropped because of its fake appearance and from these 33 women, 26 are entrepreneurs also successful in handling their business operations, other seven women are the one who takes loan but they had not been given with the autonomous ownership of that credit, they have only been used as the intermediary in passing the credit to the male family members. 26 women have efficiently implemented their businesses and also contributing enough to their household.

The information is combined in the given matrix form, which reflects the interpretative phenomenological analysis with the idiographic and nomothetic approach, the idiographic analysis has opted for interview by interview analysis although nomothetic one is the analysis of all interviews at a time. The analysis matrix is established after the procedure of transcription of interviews then followed by protocol coding, emotion coding, value coding, sorting and sifting, memoing has also been prepared. The following codes have been used in the IPA table for seeing the various responses; 
Table 4

Explanation of Codes

\begin{tabular}{ll}
\hline Codes & Explanation \\
\hline Y & Yes \\
N & No \\
YE & yes earning \\
YI & Yes Investing \\
S & same \\
LB & little bit \\
B & better \\
G & Good \\
W & worst \\
NG & not so good \\
DU & depends upon \\
ND & not directly \\
WD & withdrawn \\
NAE & not associated with the earnings \\
NI & not involved \\
Nt & not \\
NtA & Not allowed \\
\hline
\end{tabular}




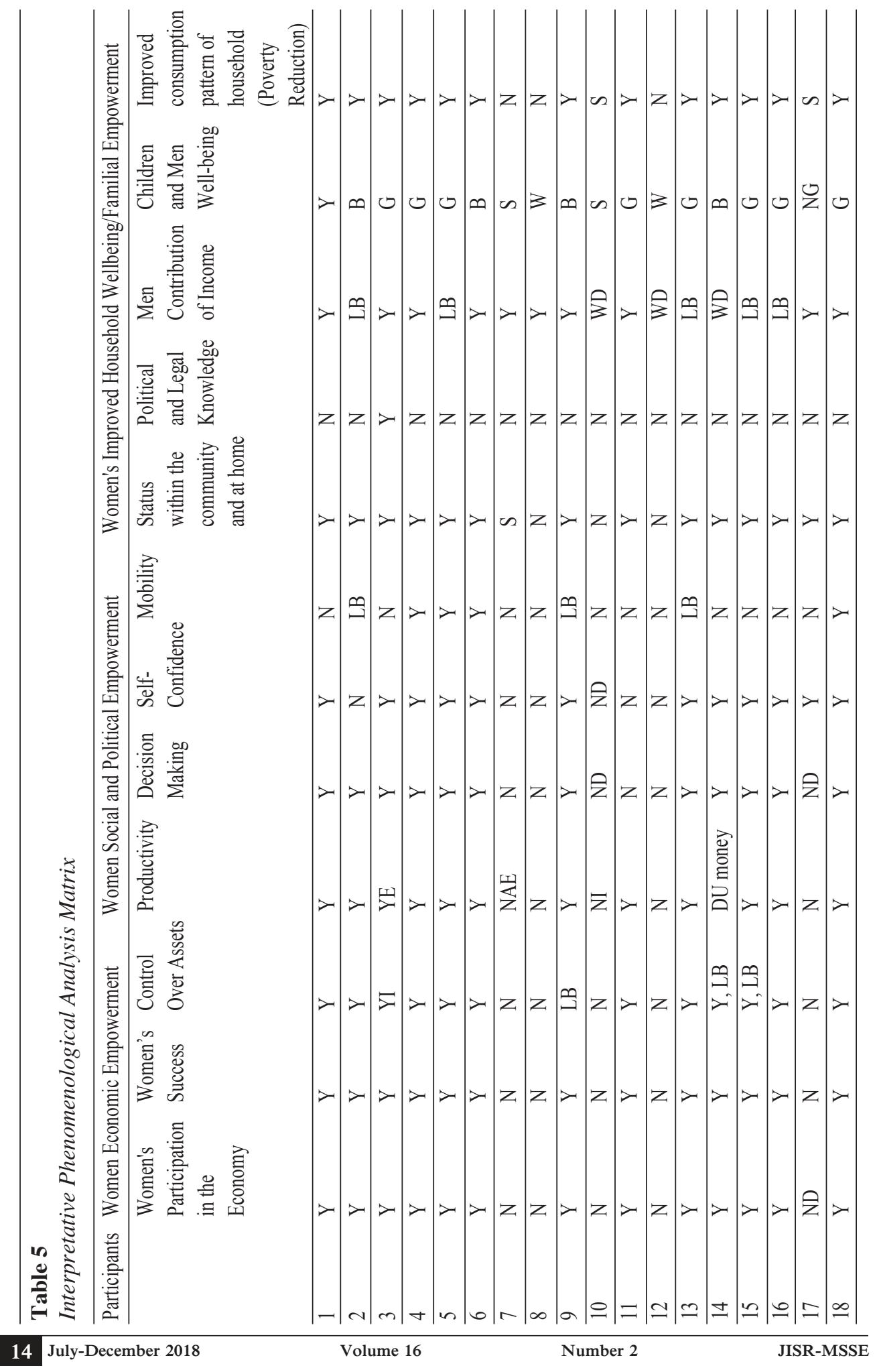




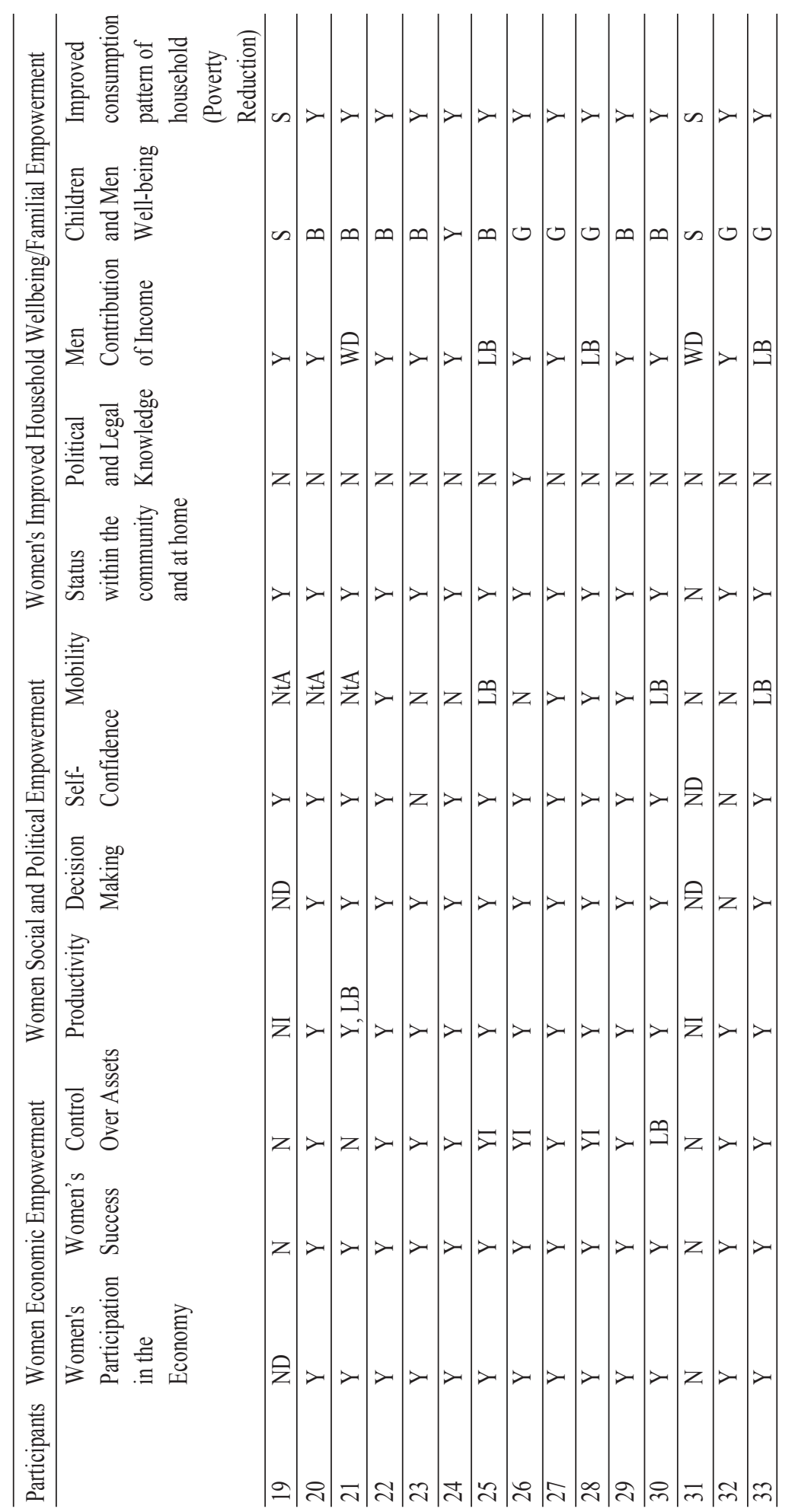


The above matrices show the responses that were coded, sorted and sifted then themes were produced in the data integration phase, the seven women are not directly participating in the economy, mean no involvement in businesses or earnings. These are the same who do not enjoy success and control over assets also they are not into productivity. Although 26 women are participating in economic activities with full enthusiasm and producing good output. Women social and political empowerment which mainly depends upon self-confidence, mobility, decision making and respect in the surrounding is the tie with the economic empowerment if they earn well then their social and political empowerment would increase. Familial empowerment has seemed in almost all cases who either invest for their own businesses or transfer credit to male family members, an overall household condition is improved.

\section{ESSENCE AND DISCUSSION}

In this study, the context was critical in making sense of empowerment. Historical moves in religious understandings, cultural and societal norms and practices, also social and commercial institutions in politics and the overall economy, previous and current political conjunctures, the nature of the district, the wide social movements and number of other contextual factors imposed on the prospects for women's empowerment. These prospects may be enabling and facilitating but as well as restricting and blocking possibilities. In this study, numbers of the factors were explored in the Sindh's context like women's political representation, legal awareness, and biasness in availing education for children, religious interpretations, and enhanced women's opportunities for doing businesses, the mobility of women, infrastructure feasibility and support to civil society. These are scrutinized against how they run down within the realities of women's lives in specific political, social, cultural, and legal contexts.

To understand the story of the women who availed loans, Kabeer (2005) points out that we require identifying the deep-rooted patterns of disempowerment for analyzing the empowerment. Equally, to make sense of how the empowerment would be realized by the women, we need to locate their current participation and contribution towards the household and society. Microcredit has had a major influence on the women financial stability and all kinds of empowerment. To grasp just how significant these kinds are, we need to know about the dynamics of empowerment in this context; sub-culture, religious believes, upper and lower Sindh, mobility in the neighborhood, financial sustainability, and self-sufficiency. The interpreted experiences of women with the microcredit were more inclined towards the positivity because the major limitation of poor rural and urban segments of Sindh's people was non-availability of money, specifically women were skilled with making Rilli 'traditional bed sheet of Sindh', distinctive Sindhi Embroidery work 'Hurmacho, nando torpyo, wadho torpyo, sheeshan jo kam, katwark jo kam', making tradition products like 'Saghi and Aghat', making clay made utensils, operating small shops and parlors, stitching clothes and the most of the rural areas' women were involved in livestock businesses. Most of the women started their own businesses by using the facility of microcredit and this financial inclusion transformed not only their lives but they influenced the whole family members. In some of the cases where the social and sub-cultural contexts were different than the urban areas, microcredit only influenced the well-being of the family but did not influence the individual woman's life. 
Mayoux (2005) highlighted that the financial inclusion plays an important role in all aspects of women's lives, from the households which are their workplaces to engagement with work, and to economic to familial empowerment. No doubt, during the in-depth interviews, it was observed that women's households were their workplaces where they were working with devotion because earning was considered as power for them when they earned they contributed in the households and provided money to their male family member. Culturally if husbands/brothers/fathers are okay and happy then the whole families are happy. So, the money provided by women to their male family members made the later happy. Amongst 33 women, 26 women said that earning money was power although out of these 26 , seven are not the micro-entrepreneurs, few just availed loans and transferred to their husbands who were running their businesses but as income generated and overall familial well-being had been enriched that's why they feel satisfied with the credit facility.

Mayoux (2005) and Golla, Malhotra, Nanda, and Mehra (2011) have conceptualized the model for empowerment in which they discuss the economic empowerment, socio-cultural, political empowerment and improved well-being. Although in Sindh every district showed the same culture with different sub-cultural values, linguistic variation, even the degree of male dominance was different. Within the sub-cultural context, socio-cultural empowerment varied in both the regions of Sindh, financial stability came to women with the permission of male family members in most of the districts of upper Sindh. Although in Thar district, only financial inclusion was not enough, for them empowerment meant to earn and invest in mitigating the hunger; for that, they needed infrastructure and other basic facilities. Skilled women from Umerkot were economically empowered in their cultural context and demanded the proper infrastructure for stitching training school and their male family members were supporting them because they needed basic necessities regardless of who earned. The mobility of women in the rural area context who was low, only a few women were moving and accessing the market even have the access to mobile phones.

The previous researches which exhibited that microcredit adds to the certainty, confidence, and pride of women and implies a positive change in their well-being are all in accordance with the outcomes. The outcomes with respect to women empowerment are more convoluted. The microcredit helps to empower women and challenges traditional gender roles which makes men responsible to earn and women to take care of household activities but now women in this study also contribute to their household income and can accommodate themselves even if the spouses are away, making them independent. As presented by Mayoux (1999) and Mitchell and Hesli (2013) women can also replace the income of the men letting them spending their own cash on themselves. In the meanwhile as according to their gender role defined by society women are supposed to be the prime guardians of the family and household activities (Mitchell \& Hesli, 2013). These outcomes have no clear conclusions and seem to be contradicting regarding women empowerment in this study. As far as political and legal empowerment is the concern, then it is negligible and few women only know about the government parties name otherwise their interest is zero and they give votes to those for whom they are told by their brothers or husbands. However, it is ought to be noticeable that the decision and ability of women restricted by the religious, cultural and social norms where women are not freely exercising their decisions and spent their earnings as per the direction of a male family member.

\begin{tabular}{llll|l}
\hline JISR-MSSE & Volume 16 & Number 2 & July-December 2018 & 17
\end{tabular}


Things which are significant to highlight here and are reflected during the interview by the participants are affording the health care facilities through which child mortality rate has decreased. Women can talk about the family planning which was not being able before. Participant Naseem said,

'Muhnji Dhee maree wayee pait kharab main ayein maan panj rupayan jee goree flagyl na wathee sagheyas cho tha munjhe murs je Dahari dihan jee so weehey rupaya ahe jehnsa biya bachra mani khaeenda howa, harein maa pesa wartha tam ta bhart bhara theen pehnjo kamaya theen ayein pesa munjhi taqat ahin'

'My daughter had died with diarrhea because I was not able to afford Rs. 5/ Flagyl tablet for her as my husband is earning Rs 120/- on the daily basis which are used for other children food and feed but now after availing credit, I am doing handmade embroidery work, earning myself, and that money is my power'

For these women, empowerment is not about exercising power on the world or on the other people like Duflo (2012) said but having three times meal, having basic health facilities, having respected and right to speak in front of the in-laws and male family members of the family, having basic facilities at home like refrigerator, washing machines. It described their empowerment. If the MFIs formulate and implement strategies for women empowerment it can help to increase the influence as well but in this case, women are targeted just because of being social trust not for empowerment.

\section{CONCLUSION}

Microfinance is a system which starts functioning from the scratch. So, it not only teaches but also learns with the passage of time from the feedback of its own thrust. Since the inception of it, women's empowerment has been its target (Ali \& Alam, 2010). Microfinance practitioners studied social structure, culture, religious usage and the status of the women in particular and came to the conclusion that keeping women folk outside the economic orbit country's development was not possible. So, women came to the priority in their thinking (Aghion \& Morduch, 2010). It was also reflected through this study that Sindh's women have a strong commitment and significant contribution in the economic activities and they are also skilled for earning but in the materialistic thing, non-availability of the resources is the main issue. Since ages women are at work but their contributions have never been recognized. They are subjugated under the whims of the male and thereby considered as the product of enjoyment (Ahmed \& Chowdhury, 2001). They are kept in protected custody and never allowed to breathe in the open air. But the fact is that their participation in the nation-building activities is the best way to secure our country's future (Bashar, M.A; 2010).

From this study, it was gauged that women economic empowerment is their financial strength which supports them in building their social status and be self-confident so they can practice the power of decision making. In this study, it is reflected that earning gives main power to women to bargain and even to speak. All other dimensions of empowerment emerge through the financial stability as also shared by the Mayoux (2008). When women earn, they can contribute towards the welfare of household in terms of better nutrition, education, health facilities which are the major problems of the poor segment of Sindhi society. Women realize 
their own empowerment in terms of better food and in some case the simple availability of food too. Familial empowerment is realized when women share the responsibilities of male family members and earn enough to live happily and consume better food. Social empowerment, as in the literature has the strong association with the economic empowerment (Ahmed, Siwar, \& Idris, 2011; Banerjee \& and Sain, 2016) but during this study, it was narrated by the women and observed that social empowerment is very weak. Due to patriarchal mindsets, cultural and social restrictions emerge and misinterpreted religious myths to become the huge obstacles in the path of the social empowerment of women.

This study shows that women feel more empowered when familial empowerment is achieved, overall family well-being and the financial stability of the family brings happiness and joy within the households where most of the women feel strengthened and stable. On the other hand, few of the women added that after utilization of the microcredit, they are under the financial burden not only this but the surged responsibility of earning along with the domestic responsibilities created tensions, they became unhappy, sustaining high pressures and become weak. So, microcredit does not only empower women but in some cases, it disempowered them and put them in the condition of poorest from poor. Therefore, women experiences vary from household to household but mostly with the right utilization and family support, microcredit plays the significant role in empowering them. Empowerment is the process and varies from culture to culture.

\section{REFERENCES}

Addai, B. (2017). Women Empowerment Through Microfinance: Empirical Evidence from Ghana. Journal of Finance and Accounting, 5(1), 1-11.

Agarwal, Y. (2016). Microfinance and Poverty Alleviation. Imperial Journal of Interdisciplinary Research (IJIR), 2(11), 1575-1577.

Aggarwal, R., Goodell, J. W., \& Selleck, L. J. (2015). Lending to women in microfinance: Role of social trust. International Business Review, 24(1), 55-65.

Aghion, B. A., \& Morduch, J. (2010). The Economics of Microfinance. London: The MIT Press.

Ahmed, F., Siwar, C., \& Idris, N. (2011). Improving Well-being of Rural Women Through Participation in Microcredit Programme: Evidence from Bangladesh. Australian Journal of Basic and Applied Sciences.

Ahmed, S. M., \& Chowdhury, M. (2001). Microcredit and Emotional Well-being: Experience of Poor Rural Women from Matlab, Bangladesh. World Development, 1957-1966.

Akram, M., \& Hussain, I. (2011). The Role of Microfinance in uplifting Income Level: A study of District Okara - Pakistan. Interdisciplinary Journal of Contemporary Research in Business, 83-94.

Ali, A., \& Alam, M. A. (2010). Role and Performance of Microcredit in Pakistan. Department of Economics and Informatics, University West.

Ali, I., \& Hatta, Z. A. (2012). Women's Empowerment or Disempowerment through Microfinance: Evidence from Bangladesh. Asian Social Work and Policy Review. 6, pp. 11-121. Blackwell Publishing Asia Pty Ltd.

Ali, K., \& Hamid, A. (2010). Problems of Working Women in The Rural Informal Sector of Punjab (Pakistan). Lahore Journal of Economics, 2(4), 89-98.

Alsop, R., \& Heinsohn, N. (2005). Measuring Empowerment in Practice: Structuring Analysis and Framing Indicators. Washington, DC: World Bank.

\begin{tabular}{llll}
\hline JISR-MSSE & Volume 16 & Number 2 & July-December 2018 \\
\hline
\end{tabular}


Anyanwu, C. (2004). Microfinance Institutions in Nigeria: Policy, Practice, and Potential. "Constraints to Growth in Sub Saharan Africa" (pp. 1-31). Pretoria, South Africa: G24 Workshop.

Aruna, M., \& Jyothirmayi, R. (2011). The role of microfinance in women empowerment: A study on the SHG bank linkage program in Hyderabad (Andhra Pradesh). Indian Journal of Commerce \& Management Studies, 77-95.

Asher, S. N., \& Haider, s. (2017). Role of Micro-Credit to Empower Women Eegarding Health and Family issues in Pakistan. Family issues in Pakistan, 4(1), 11-14.

Awojobi, O. N. (2013). Microfinance as a Strategy for Poverty Reduction: the Nigerian Experience. Berlin, Germany: Berlin School of Economics and Law.

Ayub-ul-Hasan, \& Khan, I. N. (2012). SBP Annual Performance Review. Kaachi: State Bank of Pakistan.

Banerjee, P., \& and Sain, K. (2016). A Case Study on Women Empowerment and Financial Literacy through SHGs. International Journal of Research in Economics and Social Sciences, 6(11), 295-301.

Basharat, A., Arshad, A., Abbass, S., \& Aziz, S. (2015). Pakistan Microfinance Review 2015: An Annual Assessment of the Microfinance Industry. Islamabad: Pakistan Microfinance Network.

Basher, M. A. (2010). Promotional Role of Microcredit: Evidence from the Grameen Bank of Bangladesh. Journal of International Development, 22(4), 521-529.

Basher, M. A. (2010). Promotional Role of Microcredit: Evidence from the Grameen Bank of Bangladesh. Journal of International Development, 521-529.

Bhat, R., \& Lakshmi, J. (2002). The feminization of Poverty and Empowerment of Women-An Indian Perspective \& Experience. International Women's Conference, (pp. 6-11). Townsville, Australia.

Bhatt, N., \& Tang, S. Y. (2001). Delivering Microfinance in Developing Countries: Controversies and Policy Perspectives. Policy Studies Journal, 29(2), 319-333. doi:10.1111/j.1541-0072.2001.tb02095.x

Bruno, J. (2013). Microfinance or Micro-Commercial Banking: The Great Recession's Impact on Women's Access to Microcredit in the United States. HeinOnline, 34(1).

Bui, L. T. (2014). Microfinance and Poverty Alleviation: DOES Credit Access Contribute to Reduce Household Poverty in Vietnam? Washington DC: Graduate School of Arts and Sciences.

Chaudhry, I. S., Nosheen, F., \& Lodhi, M. I. (2012). Women Empowerment in Pakistan with Special Reference to Islamic Viewpoint: An Empirical Study. Pakistan Journal of Social Sciences, 32(1), 171-183.

Chowdhury, M. J. (2008). Does the Participation in the Microcredit Programs Contribute to the Development of Women Entrepreneurship at the Household Level? Experience from Bangladesh. UNU-WIDER Project Workshop on Entrepreneurship and Economic Development. Dhaka: Center for Microfinance and Development, University of Dhaka.

Cohen, D., \& Crabtree, B. (2006, July). Semi-Structured Interviews. Retrieved from Qualitative Research Guidelines Project: http://www.qualres.org/HomeSemi-3629.html

Cole, S. (2014). Seven Women Speak Perceptions of Economic Empowerment Opportunities Among Diverse Women in Four Different Cape Town Communities Today. SIT Digital Collections

Connell, P. J. (2003). A Phenomenological Study Of The Lived Experiences of Adult Caregiving Daughters And Their Elderly Mothers. Florida: University of Florida.

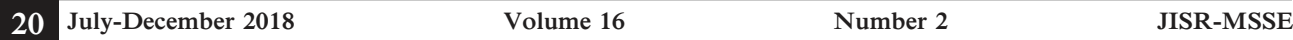


Dobra, A., \& Stiftung, F. E. (2011). Microfinance: Champion in Poverty Alleviation and Failure in Female Empowerment. Munich Personal RePEc Archive, 134-144.

Evelyn, U., \& Osifo, S. J. (2018). Microfinance and Female Entrepreneurship in Nigeria. Africa Management Review, 8(1), 36-43.

Fenton, A., Tallontire, A., \& Paavola, J. (2017). The vulnerability of microfinance institutions to climate risk in the Satkhira District, Southwest Bangladesh. London: The Centre for Climate Change Economics and Policy (CCCEP).

Finlay, L. (2009). Debating Phenomenological Research Methods. In N. Friesen, C. Henriksson, \& T. Saevi, Hermeneutic Phenomenology in Education (Vol. 4, pp. 6-25). Springer.

Gobbi, M., Dhakal, N., \& Hijazi, S. (2005). Nepal and Pakistan - micro-finance and microenterprise development: their contribution to the economic empowerment of women. Geneva: International Labour Organization.

Golla, M. A., Malhotra, A., Nanda, P., \& Mehra, R. (2011). Understanding and Measuring Women's Economic Empowerment. Internation Center for Research, 6-9.

Golla, M. A., Malhotra, A., Nanda, P., \& Mehra, R. (2011). Understanding and Measuring Women's Economic Empowerment.

Graflund, F. (2013). The Impact of Microcredit on Women's Empowerment.-A case study of Microcredit in the Tangail District, Bangladesh. Lund University.

Handayani, W. (2013). Rural-Urban Transition in Central Java: Population and Economic Structural Changes Based on Cluster Analysis. Land, 2(3), 419-436.

Hartley, D. (2007). Organizational Epistemology, Education and Social Theory. British Journal of Sociology of Education, 195-208.

Hartmann, H. (2008). Capitalism, Patriarchy, and Job Segregation by Sex. JSTOR, 137-169.

Hennink, M., Kiiti, N., Pillilger, M., \& Jayakaran, R. (2012, March). Defining Empowerment: Perspectives from International Development Organizations. Development in Practice, 22(2), 202-215. doi:http://dx.doi.org/10.1080/09614524.2012.640987

Hulme, D., \& Arun, T. (2011, November 26). What's Wrong and Right with Microfinance. Economic and Political Weekly, 46(48), 23-26. Retrieved from http://www.jstor.org/ stable/41319428

Hunt, J., \& Kasynathan, N. (2002). Reflections on Microfinance and Women Empowerment. Development Studies Network, 57, 71-75.

(2017). International Monetary Fund Pakistan. Washington DC: International Monetary Fund Washington, D.C.

Kabeer, N. (2005). Gender equality and women's empowerment: a critical analysis of the Third Millennium Development Goal. Gender and Development, 13(1), 13-24.

Kafle, N. P. (2013). Hermeneutic phenomenological research method. Bodhi, an Interdisciplinary Journal, 5, 181-200.

Kapila, M., Singla, A., \& Gupta, M. (2016). Impact of Microcredit on Women Empowerment in India: An Empirical Study of Punjab State. World Congress on Engineering.

Katheu, M. C. (2013). Factors Influencing the Success of Women Self-Help Groups in Pumwani Informal Settlements, Nairobi County, Kenya. Nairobi, Kenya: University of Nairobi.

Kim, J., Watts, C., Hargreaves, J., Ndhulovu, L., Phetla, G., Morison, L., . . Pronyk, P. (2007). Understanding the impact of the Microfinance- based Intervention on Women's Empowerment and the Reduction of Intimate Partner Violence in South Africa. American Journal of Public Health, 1794-1802.

\begin{tabular}{llll}
\hline JISR-MSSE & Volume 16 & Number 2 & July-December 2018 \\
\hline
\end{tabular}


Kumar, D., Hossain, A., \& Gope, M. C. (2013). Role of Micro Credit Program in Empowering Rural Women in Bangladesh: A Study on Grameen Bank Bangladesh Limited. Asian Business Review, 3(4), 114-120.

Kwasi, B. R., \& Seini, W. (2014). Perceptions of Small-Scale Poultry Farmers on the Effect of Micro-Credit on Livelihood in the Atwima Nwabiagya District of Ghana. IOSR Journal of Agriculture and Veterinary Science, 7(5), 57-62.

Li, Y., \& Rama, M. (2015). Firm Dynamics, Productivity Growth, and Job Creation in Developing Countries: The Role of Micro- and Small Enterprises. The World Bank Research Observer, 30(1), 3-38.

Luttrell, C., Quiroz, S., Scrutton, C., \& Bird, K. (2009). Understanding and Operationalizing Empowerment. London: Overseas Development Institute.

Malhotra, A., Schuler, S. R., \& Boender, C. (2002). Measuring Women's Empowerment as a Variable in International Development. JSI Research and Training Institute.

Mayoux, L. (2005). Women Empowerment Through Sustainable Microfinance. Pakistan: Aga Khan Foundation Canada.

Mayoux, L. (2008). Taking Gender Seriously: Towards the Gender Justice Protocol For a Diversified, Inclusive, and Sustainable Financial Sector. Canada and Pakistan: Oxfam Novib's Women's Empowerment Mainstreaming and Networking (WOMAN) programme for Gender Justice in Economic Development.

Mishi, S., \& Kapingura, F. (2012). Women's access to microfinance and poverty alleviation in Zimbabwe: the Case study of Chinhoyi town. African Journal of Business Management, 6(29), 8667-8676.

Mitchell, S. M., \& Hesli, V. L. (2013). Women don't ask? Women don't say no? Bargaining and service in the political science profession. Political Science \& Politics, 46(2), 355-369.

Muhammad, S. D. (2010). Microfinance Challenges and Opportunities in Pakistan. European Journal of Social Sciences, 14(1), 88-97.

Munir, W., \& Qasim, M. (2016). Microfinance Sector Update. Karachi: JCR-VIS Credit Rating Company Limited.

Nasir, S. (2013). Microfinance in India: Contemporary Issues and Challenges. Middle-East Journal of Scientific Research, 191-199.

(2014). National Financial Inclusion Strategy Pakistan. Karachi: State Bank of Pakistan.

(2012). Pakistan Microfinance Network: Annual Report. Islamabad: Pakistan Microfinance Network.

Pakistan ranked fourth among worst countries for women. (2017, November 29). Retrieved from Dawn: https://www.dawn.com/news/1373623

Panigrahi, R. R., \& Satapathy, S. K. (2014). Women Empowerment through Micro Finance \& Turning Challenges into Opportunities: Indian Scenario. International Journal of Innovative Research \& Development, 3(1), 310-316.

Peprah, J. A. (2012). Access to micro-credit well-being among women entrepreneurs in the Mfantsiman Municipality of Ghana. International Journal of Finance \& Banking Studies, 1(1), 1-14.

Rai, A., \& Ravi, S. (2011). Do Spouses Make Claims? Empowerment and Microfinance in India. World Development, 39(6), 913-921.

Rais, M. u., Mangan, T., Kumbhar, M. I., Hussain, A., \& Sahito, J. M. (2016). Impact of Microfinance on Income of Small Farmers in District Dadu, Sindh. Sci.Int., 28(3), ,2763-2766. 
Reichertz, J. (2007). Abduction: The Logic of Describing of Grounded Theory. In A. Bryant, \& K. Charmaz, The SAGE Handbook of Grounded Theory (pp. 214-227). London: Sage Publication.

Saigol, R. (2011). Women's Empowerment in Pakistan. Aurat Publication and Information Services Foundation.

Sammel, A. (2003). An Invitation to Dialogue: Gadamer, Hermeneutic Phenomenology, and Critical Environmental Education. Canadian Journal of Environmental Education $8(1), 155-168$.

Schreiner, M., \& Colombet, H. H. (2001). Microfinance, Regulation, and Uncollateralised Loans to Small Producers in Argentina. Microcredit and Development Policy.

Seibel, H. D. (2010). Old and the new world of microfinance in Europe and Asia. Southeast Asia's Credit Revolution: From Moneylenders to Microfinance. London: Routledge, 40-57.

Sekaran, U., \& Bougie, R. (2010). Business Research Methods (4th ed.). Wiley.

Sharma, P., \& Varma, S. K. (2008). Women empowerment through entrepreneurial activities of Self Help Groups. Indian Res. J. Ext. Edu, 8(1), 46-51.

Sinha, M., Mahapatra, S. S., Dutta, A., \& Sengupta, P. P. (2018). Microfinance and Women Empowerment: An Empirical Analysis. In R. C. Das, Handbook of Research on Microfinancial Impacts on Women Empowerment, Poverty, and Inequality (pp. 52-64). IGI Global.

Snow, D. R., \& Buss, T. F. (2001). Development and the role of microcredit. Policy Studies Journal, 29(2), 296-307.

Sohail, M. (2014). Women Empowerment and Economic Development-An Exploratory Study in Pakistan. Developing Country Studies, 5(4), 163-171.

Statistical Bulletin-November, 2017. (2018, May 15). Retrieved from State Bank of Pakistan: http://www.sbp.org.pk/reports/stat_reviews/Bulletin/2017/Nov/index.htm

State Bank of Pakistan, (2011). Strategic Framework for Sustainable Microfinance in Pakistan. Karachi: Microfinance Department, State Bank of Pakistan.

Taylor, M. (2012). The Antinomies of 'Financial Inclusion': Debt, Distress and the Workings of Indian Microfinance. Journal of Agrarian Change, 12(4), 601-610.

Ullah, M. Z., \& Sohail, D. (2013). Uncovering the Link between Micro Credit and Socio-Economic Empowerment of Women: A Case Study of Pakistan. Journal of Economics and Sustainable Development, 4(12), 9-16.

Varghese, D. (2011). Women Empowerment in Oman: A study based on Women Empowerment Index. Far East Journal of Psychology and Business, 2(2), 37-53.

Weiss, A. M., Hussain, A., \& Sathar, Z. A. (2001). Social Development, the Empowerment of Women, and the Expansion of Civil Society: Alternative Ways out of the Debt and Poverty Trap. The Pakistan Development Review, 40(4), 401-432.

Zoynul, A. M., \& Fahmida, M. (2013). Women Empowerment Through Microcredit: A Case Study of Dinajpur, Bangladesh. Studies in Business and Economics, 8(2), 5-19. 
